\title{
STEADY STATE TEMPERATURES IN A QUARTER PLANE
}

\author{
B. D. AGGARWALA and C. NASIM \\ Department of Mathematics and Statistics \\ The University of Calgary \\ Calgary, Alberta, Canada, T2N 1N4 \\ (Received October 18, 1993 and in revised form March 1, 1994)
}

\begin{abstract}
The discontinuous boundary value problem of steady state temperatures in a quarter plane gives rise to a pair of dual integral equations which are not of Titchmarch type. These dual integral equations are considered in this paper.
\end{abstract}

KEYWORDS AND PHRASES. Harmonic boundary value problems, Dual integral equations, Heat transfer.

1991 AMS SUBJECT CLASSIFICATION CODE: 45F10.

\section{INTRODUCTION.}

We consider the problem of steady state temperatures in a quarter plane (see Fig. 1), whose edge $x=0$ is losing heat to environment at zero temperature according to Newton's Law of cooling while on the edge $y=0$, temperature is controlled on portion of this edge, while the heat input is known on the remaining part. Typically, this problem is governed by:

Find $u=u(x, y)$ such that

$$
\begin{aligned}
\nabla^{2} u=\frac{\partial^{2} u}{\partial x^{2}}+\frac{\partial^{2} u}{\partial y^{2}}=0 & \text { in } \quad x>0, y>0 \\
\frac{\partial u}{\partial x}-\alpha u=0 & \text { on } x=0 \text { in } y>0
\end{aligned}
$$

and either

$$
\begin{aligned}
& \mathrm{u}(\mathrm{x}, 0)=\mathrm{f}_{1}(\mathrm{x}) \quad \text { in } \quad 0<\mathrm{x}<1 \\
& \text { and } u_{y}(x, 0)=-g_{1}(x) \text { in } x>1
\end{aligned}
$$

or

$$
u_{y}(x, 0)=-f_{1}(x) \quad \text { in } \quad 0<x<1
$$

and $\quad u=u(x, 0)=g_{1}(x)$ in $\quad x>1$.

where the subscript denotes differentiation w.r.t. that variable. Also, in each case we require that $|u|$ be bounded at infinity.

An appropriate representation for $u=u(x, y)$ in this case is

$$
u(x, y)=\int_{0}^{\infty} f(t)\left(\alpha \sin x t+t \cos x^{t}\right) e^{-t y} d t \quad \text { in } x>0, y>0
$$


where $f(t)$ is governed by the following two cases:

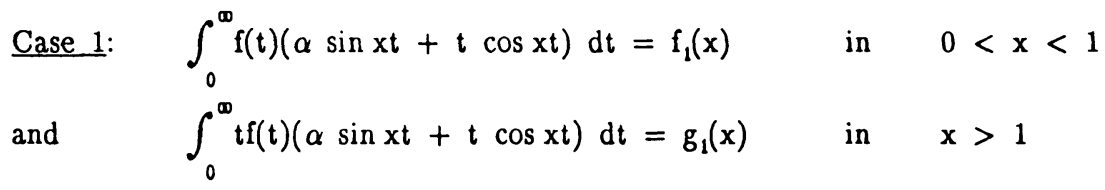

or

Case 2: $\quad \int_{0}^{\infty} \mathrm{tf}(\mathrm{t})(\alpha \sin \mathrm{xt}+\mathrm{t} \cos \mathrm{xt}) \mathrm{dt}=\mathrm{f}_{\mathrm{t}}(\mathrm{x}) \quad$ in $\quad 0<\mathrm{x}<1$

and

$$
\int_{0}^{\infty} f(t)(\alpha \sin x t+t \cos x t) d t=g_{1}(x) \quad \text { in } \quad x>1
$$

respectively.

We propose to solve such dual integral equations for the function $f(t)$ in this paper. We point out that these equations are not of Titchmarch type (because the kernel $k(x, t)=\alpha \sin x t+t \cos x t$ is not a Fourier Kernel) and to our knowledge, have not been considered before. While the kernel $k(x, t)$ has been successfully inverted [1, page 70], dual integral equations involving this kernel have not been considered previously. We shall attempt only a formal solution of these dual integral equations, and shall assume - throughout that the functions $f_{1}(x)$ and $g_{1}(x)$ are continuous in $0 \leq x \leq 1$ and in $x \geq 1$ respectively.

2. METHOD OF SOLUTION.

We shall assume that the integrals $\int_{0}^{\infty} f(t) \sin x t d t, \int_{0}^{\infty} t f(t) \sin x t d t, \int_{0}^{\infty} t f(t) \cos x t d t$ and $\int_{0}^{\infty} t^{2} f(t) \cos x t d t$ exist, in which case,

$$
\int_{0}^{\infty} f(t) \sin x t d t=F(x) \Rightarrow \int_{0}^{\infty} t f(t) \cos x t d t=F^{\prime}(x)
$$

and $\int_{0}^{\infty} t f(t) \sin x t d t=G(x) \Rightarrow \int_{0}^{\infty} t^{2} f(t) \cos x t d t=G^{\prime}(x)$

Equation (2.1) implies that $\operatorname{Lim}_{x \rightarrow 0^{+}} F(x)=F(0)=0$ and with this notation, our dual integral equations (1.5) in the first case become,

$$
\alpha F(x)+F^{\prime}(x)=f_{1}(x) \text { in } \quad 0<x<1
$$

and $\alpha G(x)+G^{\prime}(x)=g_{1}(x)$ in $\quad x>1$

with the condition that $F(0)=0$.

In the second case (1.6), we write

$$
F(x)=\int_{0}^{\infty} t f(t) \sin x t d t, \quad 0<x<1
$$

and $G(x)=\int_{0}^{\infty} f(t) \sin x t d t, \quad x>1$

so that we again get equations (2.3) with condition (2.4).

And for both the cases, the equations (2.3) give

$$
F(x)=e^{-\alpha x} \int_{0}^{x} e^{\alpha t} f_{1}(t) d t, \quad 0<x<1,
$$


and $G(x)=e^{-\alpha x} \int_{1}^{x} e^{\alpha t} g_{1}(t) d t,+B e^{-\alpha x}$ in $\quad x>1$,

It remains to determine the constant $B$. We shall determine this constant by the (physically realistic) condition that the quantity $u(x, 0)$ is continuous at $x=1$.

3. SOLUTION FOR THE FIRST CASE.

In this case, the dual integral equations (1.5) are reduced to dual equations

$\int_{0}^{\infty} f(t) \sin x t d t=F(x)=e^{-\alpha x} \int_{0}^{x} e^{\alpha t} f_{1}(t) d t \quad$ in $0<x<1$

and $\int_{0}^{\infty} t f(t) \sin x t d t=e^{-\alpha x} \int_{1}^{x} e^{\alpha t} g_{1}(t) d t+B e^{-\alpha x}$ in $\quad x>1$.

These equations give [2]

$$
\begin{aligned}
& f(t)=\int_{0}^{1} u J_{0}(u t) f_{2}(u) d u+\int_{1}^{\infty} u J_{0}(u t) g_{2}(u) d u \\
& +\frac{2 B}{\pi} \int_{1}^{\infty} u J_{0}(u t)\left[\int_{u}^{\infty} \frac{e^{-\infty x}}{\sqrt{x^{2}-u^{2}}} d x\right] d u
\end{aligned}
$$

where

$$
f_{2}(u)=\frac{2}{\pi} \frac{d}{d u} \int_{0}^{u} \frac{x F(x)}{\sqrt{u^{2}-x^{2}}} d x=\frac{2}{\pi} \int_{0}^{u} \frac{F^{\prime}(x)}{\sqrt{u^{2}-x^{2}}} d x
$$

and $g_{2}(u)=\frac{2}{\pi} \int_{u}^{\infty} \frac{e^{-\alpha x}}{\sqrt{x^{2}-u^{2}}}\left[\int_{1}^{x} g_{1}(t) e^{\alpha t} d t\right] d x$.

In deriving equation (3.3a), we have used the fact that $F(0)=0$.

To determine $B$, we now substitute this expression for $f(t)$ in $u(x, 0)$ as given by equation (1.4) above and require that

$$
\operatorname{Lim}_{x \rightarrow 1^{+}} u(x, 0)=\operatorname{Lim}_{x \rightarrow 1^{-}} u(x, 0)=\alpha F(1)+F^{\prime}(1)=f_{1}(1) .
$$

Noting that [3]

$$
\int_{u}^{\infty} \frac{e^{-\alpha x}}{\sqrt{x^{2}-u^{2}}} d x=K_{0}(\alpha u)
$$

where $\mathrm{K}$ denotes the Modified Bessel Function, we have

$$
\operatorname{Lim}_{x \rightarrow 1^{+}} u(x, 0)=\operatorname{Lim}_{x \rightarrow 1^{+}}\left(\alpha H(x)+H^{\prime}(x)\right),
$$

where for $x>1$,

$H(x)=\int_{0}^{\infty} f(t) \sin x t d t=\int_{0}^{1} \frac{u f_{2}(u)}{\sqrt{x^{2}-u^{2}}} d u+\int_{1}^{x} \frac{u g_{2}(u)}{\sqrt{x^{2}-u^{2}}} d u+\frac{2 B}{\pi} \int_{1}^{x} \frac{u K_{0}(\alpha u)}{\sqrt{x^{2}-u^{2}}} d u$.

Integration by parts gives

$$
\begin{aligned}
& \mathrm{H}(\mathrm{x})=\left[\mathrm{g}_{2}(1)-\mathrm{f}_{2}(1)+\frac{2 \mathrm{~B}}{\pi} \mathrm{K}_{0}(\alpha)\right] \sqrt{\mathrm{x}^{2}-1}+\int_{0}^{1} \mathrm{f}_{2}^{\prime}(\mathrm{u}) \sqrt{\mathrm{x}^{2}-\mathrm{u}^{2}} \mathrm{du} \\
& +\int_{1}^{\mathrm{x}} \mathrm{g}_{2}^{\prime}(\mathrm{u}) \sqrt{\mathrm{x}^{2}-\mathrm{u}^{2}} \mathrm{du}-\frac{2 \mathrm{~B}}{\pi} \int_{1}^{\mathrm{x}} \alpha \mathrm{K}_{1}(\alpha u) \sqrt{\mathrm{x}^{2}-\mathrm{u}^{2}} \mathrm{dx}+\mathrm{f}_{2}(0) \mathrm{x} .
\end{aligned}
$$

At this stage, we notice that unless the co-efficient of $\sqrt{x^{2}-1}$ in the expression for $\mathrm{H}(\mathrm{x})$ is zero, $\mathrm{H}^{\prime}(\mathrm{x})$ will be unbounded as $\mathrm{x} \rightarrow 1^{+}$, and then $\mathrm{u}(\mathrm{x}, 0)$ cannot be continuous at $x=1$. We therefore put this co-efficient to zero to obtain 


$$
\mathrm{B}=\frac{\pi}{2} \frac{\mathrm{f}_{2}(1)-\mathrm{g}_{2}(1)}{\mathrm{K}_{0}(\alpha)}
$$

This gives the value of $B$ in terms of the quanitites $f_{2}(1)$ and $g_{2}(1)$ which are known from the data. We shall now show that with this value of $B, u(x, 0)$ is continuous at $\mathbf{x}=1$. We have for $\mathbf{x}>1$,

$$
\begin{aligned}
& \alpha H(x)+H^{\prime}(x)=\alpha \int_{0}^{1} f_{2}^{\prime}(u) \sqrt{x^{2}-u^{2}} d u+\alpha \int_{1}^{x} g_{2}^{\prime}(u) \sqrt{x^{2}-u^{2}} d u \\
& +\int_{0}^{1} \frac{x f_{2}^{\prime}(u)}{\sqrt{x^{2}-u^{2}}} d u+\int_{1}^{x} \frac{x_{2}^{\prime}(u)}{\sqrt{x^{2}-u^{2}}} d u-\frac{2 B}{\pi} \int_{1}^{x} \alpha^{2} K_{1}(\alpha u) \sqrt{x^{2}-u^{2}} d u \\
& -\frac{2 B}{\pi} \int_{1}^{x} \frac{x \alpha K_{1}(\alpha u)}{\sqrt{x^{2}-u^{2}}} d u+(1+\alpha x) f_{2}(0)
\end{aligned}
$$

so that, after some simplification, we obtain

$$
\operatorname{Lim}_{x \rightarrow 1^{+}}\left(\alpha H(x)+H^{\prime}(x)\right)=\alpha \int_{0}^{1} \frac{u f_{2}(u)}{\sqrt{1-u^{2}}} d u+\int_{0}^{1} \frac{f_{2}^{\prime}(u)}{\sqrt{1-u^{2}}} d u+f_{2}(0) .
$$

Also $f_{2}(u)=\frac{2}{\pi} \int_{0}^{u} \frac{F^{\prime}(x)}{\sqrt{u^{2}-x^{2}}} d x$

$$
=\frac{2}{\pi} \quad F^{\prime \prime}(0) u+\frac{2}{\pi} \int_{0}^{u}\left[\frac{F^{\prime}(x)-F^{\prime}(0)}{x}\right]^{\prime} \sqrt{u^{2}-x^{2}} d x+F^{\prime}(0)
$$

so that

$$
\mathrm{f}_{2}^{\prime}(\mathrm{u})=\frac{2}{\pi} \mathrm{F}^{\prime \prime}(0)+\frac{2}{\pi} \int_{0}^{\mathrm{u}}\left[\frac{\mathrm{F}^{\prime}(\mathrm{x})-\mathrm{F}^{\prime}(0)}{\mathrm{x}}\right]^{\prime} \frac{\mathrm{u}}{\sqrt{\mathrm{u}^{2}-\mathrm{x}^{2}}} \mathrm{dx} .
$$

Substituting the values of $f_{2}(u)$ and $f_{2}^{\prime}(u)$ in the expression for $\operatorname{Lim}_{x \rightarrow 1^{+}}\left(\alpha H(x)+H^{\prime}(x)\right)$; interchanging the order of integration, and using the fact that

we obtain

$$
\int_{x}^{y} \frac{u d u}{\sqrt{\left(u^{2}-x^{2}\right)\left(y^{2}-u^{2}\right)}}=\frac{\pi}{2}, \quad y>x>0,
$$

$$
\begin{aligned}
\operatorname{Lim}_{x \rightarrow 1^{+}}\left(\alpha H(x)+H^{\prime}(x)\right) & =\alpha(F(1)-F(0))+F^{\prime \prime}(0) \\
& +\left(F^{\prime}(1)-F^{\prime}(0)\right)-F^{\prime \prime}(0)+f_{2}(0) \\
& =\alpha F(1)+F^{\prime}(1) .
\end{aligned}
$$

This proves the continuity of $u(x, 0)$ at $x=1$. It can also be seen that if $B$ is given by (3.8), then under suitable restrictions on the data, $u(x, 0)$ as given by equation (3.9) is bounded as $x \rightarrow \infty$.

4. SOLUTION FOR THE SECOND CASE.

In this case, the dual equations (1.6) are reduced to

$$
\int_{0}^{\infty} \operatorname{tf}(\mathrm{t}) \sin x t d t=F(x)=e^{-\alpha x} \int_{0}^{x} f_{1}(t) e^{\alpha t} d t, \quad 0<x<1
$$

and $\int_{0}^{\infty} f(t) \sin x t d t=e^{-\alpha x} \int_{1}^{x} e^{\alpha t} g_{1}(t) d t+\mathrm{Ce}^{-\alpha x}, \quad x>1$

$$
=\mathrm{h}(\mathrm{x})+\mathrm{Ce}^{-\alpha \mathrm{x}} \text {, say. }
$$

The solution $f(t)$ is now given by 
$f(t)=\frac{2}{\pi} \int_{0}^{1} J_{1}(u t) h_{1}(u) d u-\frac{2}{\pi} \int_{1}^{\infty} u J_{1}(u t) h_{2}(u) d u+\frac{2 C \alpha}{\pi} \int_{1}^{\infty} u J_{1}(u t) K_{1}(\alpha u) d u$

where

$$
\begin{aligned}
& h_{1}(u)=\int_{0}^{u} \frac{x F(x)}{\sqrt{u^{2}-x^{2}}} d x \text {, and } \\
& h_{2}(u)=\frac{d}{d u} \int_{u}^{\infty} \frac{h(x)}{\sqrt{x^{2}-u^{2}}} d x .
\end{aligned}
$$

Proceeding as in section 3 , and assuming that the data $g_{1}(x)$ is suitably restricted so that $h_{2}(w)=0$, we get, for $x<1$,

$$
\begin{aligned}
& \mathrm{u}(\mathrm{x}, 0)=\alpha \mathrm{H}(\mathrm{x})+\mathrm{H}^{\prime}(\mathrm{x}) \text {, where } \\
& \mathrm{H}(\mathrm{x})=\frac{2 \mathrm{x}}{\pi} \sqrt{1-\mathrm{x}^{2}}\left[\mathrm{~h}_{1}(1)+\mathrm{h}_{2}(1)-\mathrm{C} \alpha \mathrm{K}_{1}(\alpha)\right] \\
& +\frac{2 \mathrm{x}}{\pi} \int_{1}^{\infty}\left[\frac{\mathrm{h}_{2}(\mathrm{u})-\mathrm{C} \alpha \mathrm{K}_{1}(\alpha \mathrm{u})}{\mathrm{u}}\right]^{\prime} \sqrt{\mathrm{u}^{2}-\mathrm{x}^{2}} \mathrm{du}-\frac{2 \mathrm{x}}{\pi} \int_{x}^{1}\left[\frac{\mathrm{h}_{1}(\mathrm{u})}{\mathrm{u}^{2}}\right]^{\prime} \sqrt{\mathrm{u}^{2}-\mathrm{x}^{2}} d u
\end{aligned}
$$

and for $u(x, 0)$ to be continuous at $x=1$, we must have

$$
C=\frac{h_{1}(1)+h_{2}(1)}{\alpha K_{1}(\alpha)}
$$

With this value of $C$, we have

$\operatorname{Lim}_{x \rightarrow 1^{-}}\left[\left(\alpha H(x)+H^{\prime}(x)\right]=\frac{2(1+\alpha)}{\pi} \int_{1}^{\infty}\left[\frac{h_{2}(u)}{u}\right]^{\prime} \sqrt{u^{2}-1} d u-\frac{2}{\pi} \int_{1}^{\infty}\left[\frac{h_{2}(u)}{u}\right]^{\prime} \frac{1}{\sqrt{u^{2}-1}} d u\right.$.

Also,

$$
\begin{aligned}
h_{2}(u) & =\frac{d}{d u} \int_{u}^{\infty} \frac{h(x)}{\sqrt{x^{2}-u^{2}}} d x \\
\Rightarrow \quad & h(x)=-\frac{2 x}{\pi} \int_{x}^{\infty} \frac{h_{2}(u)}{\sqrt{u^{2}-x^{2}}} d u .
\end{aligned}
$$

Differentiating equation (4.9) and substituting in (4.7), we get

$$
\operatorname{Lim}_{x \rightarrow 1^{-}}\left[\alpha H(x)+H^{\prime}(x)\right]=\alpha h(1)+h^{\prime}(1)=g_{1}(1)
$$

which shows that with $C$ given by equation (4.6), $u(x, 0)$ is continuous at $x=1$.

5. THE CASE $\alpha=0$.

The case of $\alpha=0$ is completely different, because for bounded $u$, the representation

$$
u(x, y)=\int_{0}^{\infty} f(t)(\alpha \sin x t+t \cos x t) e^{-t y} d t
$$

is no more valid. The correct representation now is

$$
u(x, y)=C_{1}+\int_{0}^{\infty} t f(t)(\cos x t) e^{-t y} d t .
$$

where $C_{1}$ is a constant.

Therefore, the dual integral equations this time are:

Case 1: Find $C_{1}$ and $f(t)$ such that

$$
C_{1}+\int_{0}^{\infty} t f(t) \cos x t d t=f_{1}(x) \text { in } 0<x<1
$$


and $\int_{0}^{\infty} t^{2} f(t) \cos x t d t=g_{1}(x) \quad$ in $\quad x>1$.

And,

Case 2: Find $\mathrm{C}_{1}$ and $\mathrm{f}(\mathrm{t})$, such that

$$
\int_{0}^{\infty} t^{2} f(t) \cos x t d t=f_{1}(x) \quad \text { in } \quad x<1
$$

and $C_{1}+\int_{0}^{\infty} t f(t) \cos x t d t=g_{1}(x) \quad$ in $\quad x>1$.

In case $2, C_{1}$ is that constant, if any, for which $\left|g_{1}(x)-C_{1}\right| \rightarrow 0$ as $x \rightarrow$ w. Let us consider dual equations (5.2) in Case 1 . We shall again determine $C_{1}$, by the requirement that $u(x, 0)$ is continuous at $x=1$. We have from (5.2)

$$
\text { and } \begin{aligned}
\int_{0}^{\infty} t f(t) \cos x t d t & =f_{1}(x)-C_{1}, \quad 0<x<1 \\
& \int_{0}^{\infty} t f(t) \sin x t d t=-\int_{x}^{\infty} g_{1}(x) d x=g(x), \text { say. }
\end{aligned}
$$

This gives

$$
f(t)=\frac{2}{\pi} \int_{0}^{1} u J_{0}(u t) F_{1}(u) d u+\frac{2}{\pi} \int_{1}^{\infty} u J_{0}(u t) G_{1}(u) d u-C_{1} \int_{0}^{1} u J_{0}(u t) d u
$$

where

$$
F_{1}(u)=\int_{0}^{u} \frac{f_{1}(x) d x}{\sqrt{u^{2}-x^{2}}} \text { and } G_{1}(u)=\int_{u}^{\infty} \frac{g(x)}{\sqrt{x^{2}-u^{2}}} d x \text {. }
$$

For $x>1$, we have $u(x, 0)-C_{1}=\frac{d}{d x} \int_{0}^{\infty} f(t)$ sinxt dt $=H^{\prime}(x)$ say, where after substituting the value of $f(t)$ from $(5,5)$ and simplifying, we obtain

$$
\begin{aligned}
& H(x)=\int_{0}^{\infty} f(t) \sin x t d t=\frac{2}{\pi} \sqrt{x^{2}-1}\left[G_{1}(1)-F_{1}(1)+\frac{\pi}{2} C_{1}\right]+\frac{2}{\pi} F_{1}(0) x-C_{1} x \\
& +\frac{2}{\pi} \int_{0}^{1} F_{1}^{\prime}(u) \sqrt{x^{2}-u^{2}} d u+\frac{2}{\pi} \int_{1}^{x} G_{1}^{\prime}(u) \sqrt{x^{2}-u^{2}} d u .
\end{aligned}
$$

And in order for $u(x, 0)$ to be continuous at $x=1$, we must have

$$
C_{1}=\frac{2}{\pi}\left[F_{1}(1)-G_{1}(1)\right] \text {. }
$$

With this value of $C_{1}$, it is easy to see that

$$
\begin{aligned}
& \operatorname{Lim}_{x \rightarrow 1^{+}} u(x, 0)=\operatorname{Lim}_{x \rightarrow 1^{+}} H^{\prime}(x)+C_{1} \\
& =\frac{2}{\pi} F_{1}(0)+\frac{2}{\pi} \int_{0}^{1} \frac{F_{t}^{\prime}(u)}{\sqrt{1-u^{2}}} d u
\end{aligned}
$$

Now from above,

$$
\begin{aligned}
F_{1}(u) & =\int_{0}^{u} \frac{f_{1}(x)}{\sqrt{u^{2}-x^{2}}} d x, \\
\Rightarrow \quad f_{1}(x) & =\frac{2}{\pi} \frac{d}{d x} \int_{0}^{x} \frac{u F_{1}(u)}{\sqrt{x^{2}-u^{2}}} d u
\end{aligned}
$$




$$
=\frac{2}{\pi} F_{1}(0)+\frac{2}{\pi} \times \int_{0}^{x} \frac{F_{1}^{\prime}(u)}{\sqrt{x^{2}-u^{2}}} d u .
$$

Hence from (5.9),

$$
\operatorname{Lim}_{x \rightarrow 1^{+}} u(x, 0)=f_{1}(1)
$$

which implies continuity of $u(x, 0)$ at $x=1$.

Once again, it can be seen from (5.7) that if $g_{1}(x)$ is suitably restricted then $u(x, 0)$ is bounded as $\mathbf{x} \rightarrow \infty$.

For Case 2, the solution is given by (4.2) in the limit as $\alpha \rightarrow 0^{+}$.

It should be pointed out that the problem posed by equations (5.2) has been considered by Sneddon [4, page 99]. Sneddon considers the problem (5.2) with $C_{1}=0$ and $g_{1}(x)=0$. He then imposes the condition that the heat input on $y=0$ must remain finite as $x \rightarrow 1^{-}$and arrives at the conclusion that we must have $F_{1}(1)=0$. All this, however, is a special case of our equation (5.8) wherein if $C_{1}=0$ and $G_{1}(1)=0$, we get $F_{1}(1)=0$. It would appear therefore that this problem ought to be posed as we have done it.

For the particular case of $g_{1}(x)=0$, the problem posed by equations (5.3) has also been considered by Sneddon [5, page 26]. For this particular case, our solution coincides with his.

We shall now consider some special cases.

\section{SOME SPECIAL CASES}

We consider the dual integral equations

$$
\int_{0}^{\infty} f(t)(\alpha \sin x t+t \cos x t) d t=f_{1}(x), \quad 0<x<1
$$

and $\int_{0}^{\infty} \operatorname{tf}(t)(\alpha \sin x t+t \cos x t) d t=0, \quad x>1$.

with the (additional) requirement that the quantity $\int_{0}^{\infty} f(t)(\alpha \sin x t+t \cos x t) d t$ is continuous at $\mathbf{x}=1$.

We give results for various special cases:

1. $\mathrm{f}_{1}(\mathrm{x})=1$ in $0<\mathrm{x}<1$

In this case

$$
f(t)=\int_{0}^{1} u J_{0}(u t) f_{2}(u) d u+\frac{f_{2}(1)}{K_{0}(\alpha)} \int_{1}^{\infty} u J_{0}(u t) K_{0}(\alpha u) d u
$$

where $\quad f_{2}(u)=\frac{2}{\pi} \int_{0}^{u} \frac{e^{-\alpha x}}{\sqrt{u^{2}-x^{2}}} d x$.

2. $\mathrm{f}_{1}(\mathrm{x})=1+\alpha \mathrm{x} \quad$ in $0<\mathrm{x}<1$.

In this case

$$
f(t)=\frac{J_{1}(t)}{t}+\frac{1}{K_{0}(\alpha)} \int_{1}^{\infty} u J_{0}(u t) K_{0}(\alpha u) d u
$$




$$
\text { and } \quad \begin{aligned}
\mathrm{u}(\mathrm{x}, 0) & =\int_{0}^{\infty} \mathrm{f}(\mathrm{t})(\alpha \sin \mathrm{xt}+\mathrm{t} \cos \mathrm{xt}) \mathrm{dt} \text { is given by } \\
\mathrm{u}(\mathrm{x}, 0) & =1+\alpha \mathrm{x}, \quad \mathrm{x} \leq 1 \\
& =1+\alpha \mathrm{x}-\frac{\alpha^{2}}{\mathrm{~K}_{0}(\alpha)} \int_{1}^{\mathrm{x}} \mathrm{K}_{1}(\alpha \mathrm{u}) \sqrt{\mathrm{x}^{2}-\mathrm{u}^{2}} \mathrm{du} \\
& -\frac{\alpha \mathrm{x}}{\mathrm{K}_{0}(\alpha)} \int_{1}^{\mathrm{x}} \frac{\mathrm{K}_{1}(\alpha \mathrm{u})}{\sqrt{\mathrm{x}^{2}-\mathrm{u}^{2}}} \mathrm{du}, \quad \mathrm{x} \geq 1 .
\end{aligned}
$$

For numerical calculations, it is more convenient to write

$$
\begin{aligned}
\mathrm{u}(\mathrm{x}, 0) & =1+\alpha \mathrm{x}-\frac{\mathrm{K}_{1}(\alpha)}{\mathrm{K}_{0}(\alpha)} \alpha \mathrm{x} \sqrt{\mathrm{x}^{2}-1} \\
& +\frac{\alpha^{2}}{\mathrm{~K}_{0}(\alpha)} \int_{1}^{\mathrm{x}}\left[\frac{\mathrm{x}}{\mathrm{u}} \mathrm{K}_{2}(\alpha u)-\mathrm{K}_{1}(\alpha u)\right] \sqrt{\mathrm{x}^{2}-\mathrm{u}^{2}} \mathrm{du}, \quad \mathrm{x} \geq 1 .
\end{aligned}
$$

For $\alpha=0$, we get $\mathrm{u}(\mathrm{x}, 0)=1, \mathrm{x} \geq 1$ which is correct. For $\alpha>0$, the graphs of $u(x, 0) /(1+\alpha)$ for various values of $\alpha$ are given in Figure 2 .

3. For $f_{1}(x)=\alpha x^{2}+2 x$, we get

$$
f(t)=\frac{4}{\pi} \int_{0}^{1} u^{2} J_{0}(u t) d u+\frac{4}{\pi K_{0}(\alpha)} \int_{1}^{\infty} u J_{0}(u t) K_{0}(\alpha u) d u
$$

and so on. It is easy to obtain $f(t)$ for $f_{1}(x)=\alpha x^{p}+p x^{p-1}, p \geq 1$, and then by superposition, for any analytic function $f_{1}(x)$.

As a final example, we take $\alpha=0$ and take $f_{1}(x)=x^{p}, p>0$, and $g_{1}(x)=0$ in (5.2). The resulting problem is: Find $C_{1}$ and $f(t)$ such that

$$
C_{1}+\int_{0}^{\infty} t f(t) \cos x t d t=x^{p} \quad \text { in } 0<x<1
$$

and $\int_{0}^{\infty} t^{2} f(t) \cos x t d t=0 \quad$ in $\quad x>1$.

We find

$$
\mathrm{C}_{1}=\frac{1}{\sqrt{\pi}} \frac{\Gamma[(\mathrm{p}+1) / 2]}{\Gamma[(\mathrm{p}+2) / 2]}
$$

and $f(t)=C_{1} \int_{0}^{1} u^{p+1} J_{0}(u t) d u-C_{1} \int_{0}^{1} u J_{0}(u t) d u$

and then

$$
\begin{aligned}
& \mathrm{u}(\mathrm{x}, 0)=\mathrm{C}_{1}+\int_{0}^{\infty} \mathrm{tf}(\mathrm{t}) \cos \mathrm{xt} d \mathrm{t} \quad=\mathrm{x}^{\mathrm{p}} \quad \text { in } 0 \leq \mathrm{x} \leq 1 \\
&=\mathrm{C}_{1} \int_{0}^{1} \frac{\mathrm{pu}^{\mathrm{p}-1} \mathrm{x}}{\sqrt{\mathrm{x}^{2}-\mathrm{u}^{2}}} \mathrm{du} \quad \text { in } \mathrm{x} \geq 1 .
\end{aligned}
$$

For $p=0$, we get $f(t)=0, C_{1}=1$, which is correct.

Some other interesting cases are:

$$
\begin{aligned}
& \mathrm{p}=1 \Rightarrow \mathrm{u}(\mathrm{x}, 0)=\mathrm{x} \\
& =\frac{2}{\pi} \times \sin ^{-1}\left[\frac{1}{x}\right] \\
& \mathrm{p}=2 \Rightarrow \mathrm{u}(\mathrm{x}, 0)=\mathrm{x}^{2} \\
& \text { in } \quad 0 \leq x \leq 1 \\
& \text { in } x \geq 1 \text {, } \\
& \text { in } 0 \leq x \leq 1
\end{aligned}
$$




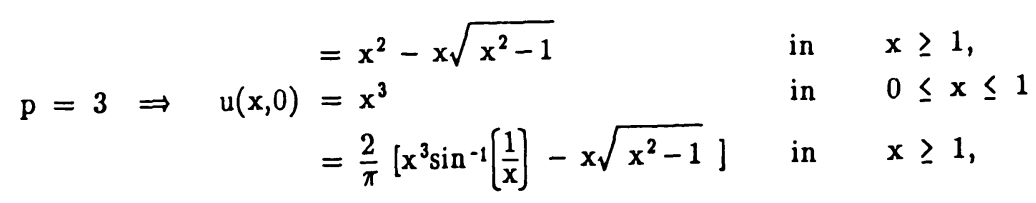

and so on.

The graphs of $u(x, 0)$ for several values of $p$ are given in Fig. 3 .

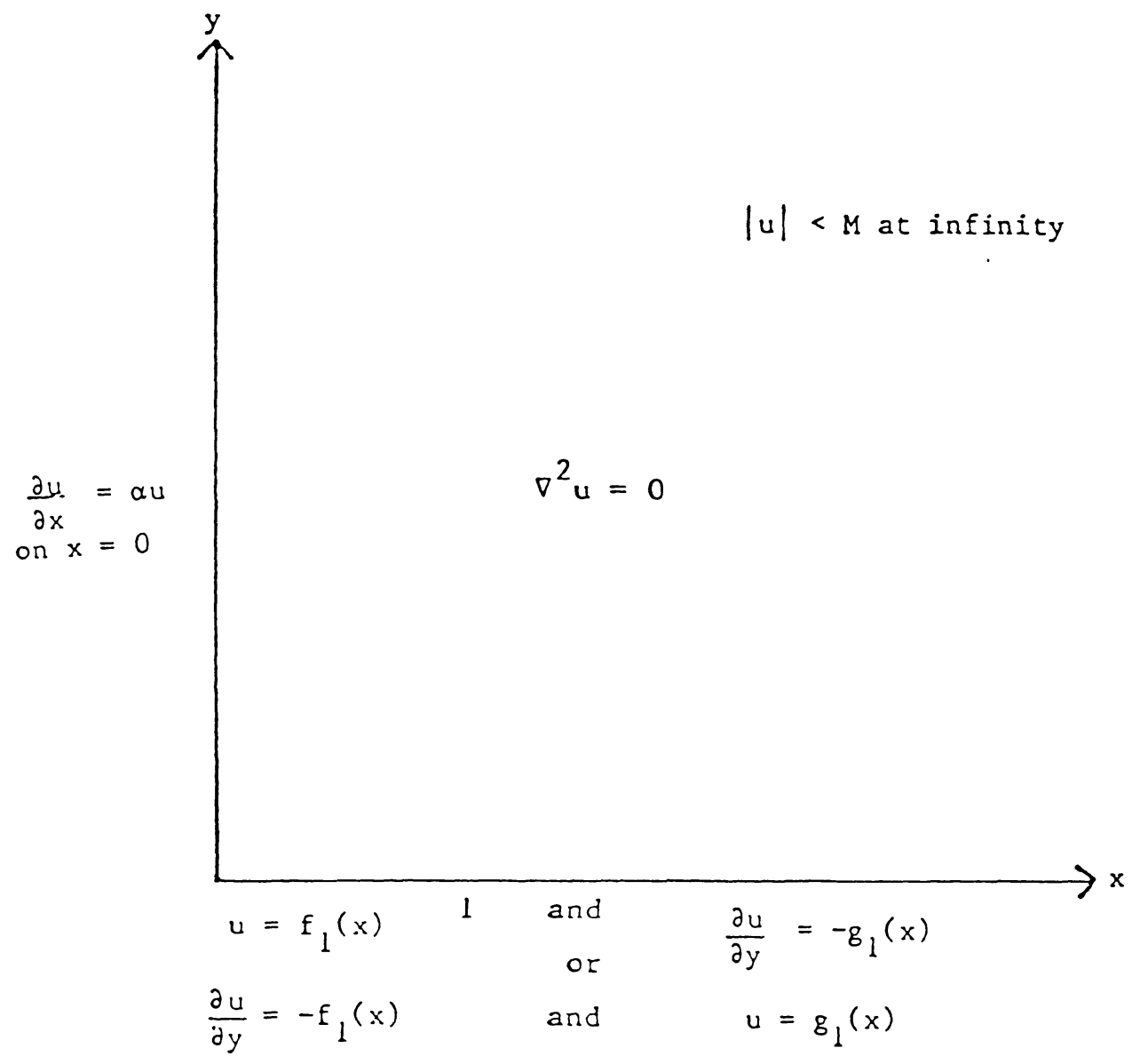

F I G. 1 - The Problem 


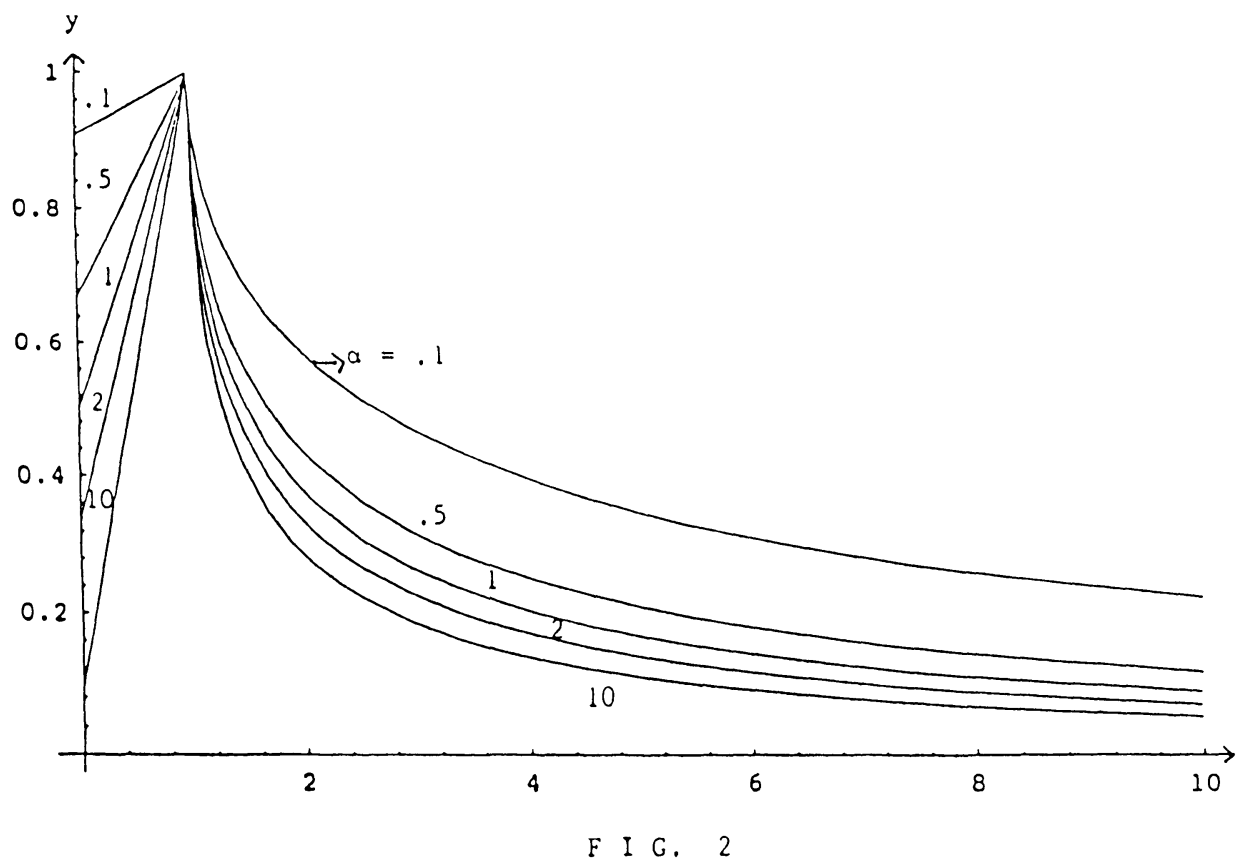

Values of $y=u(x, 0) /(1+\alpha)$, equation (6.5), for several values of $\alpha$.

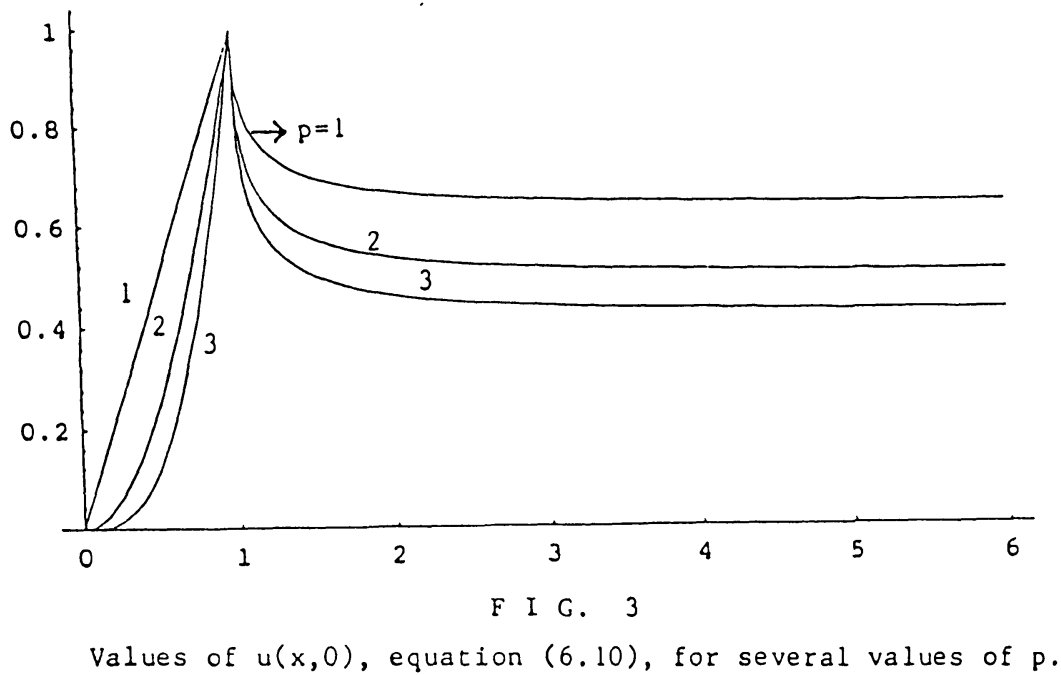

\section{REFERENCES}

1. SNEDDON, I.N., The use of Integral Transforms, McGraw Hill Book Company (1972).

2. NASIM, C., and AGGARWALA, B.D. On some dual integral equation. Indian. J. Pure Appl. Math. 15 (3), 323-340, 1984.

3. ERDELYT et al, Tables of Integral Transforms, Vol. I, Bateman Manuscript Project, McGraw Hill Book Co. Inc., New York, (1954).

4. SNEDDON, I.N., Mixed Boundary Value Problems in Potential Theory, John Wiley and Sons Inc., New York, (1966).

5. SNEDDON, I.N., Crack Problems in the Classical Theory of Elasticity, John Wiley and Sons, Inc., New York, (1969). 


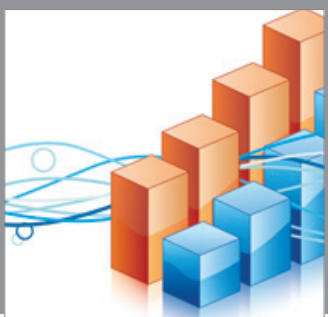

Advances in

Operations Research

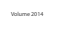

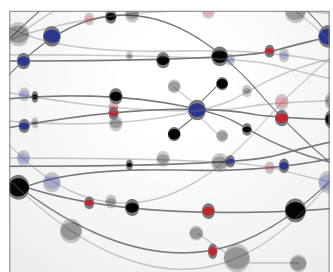

\section{The Scientific} World Journal
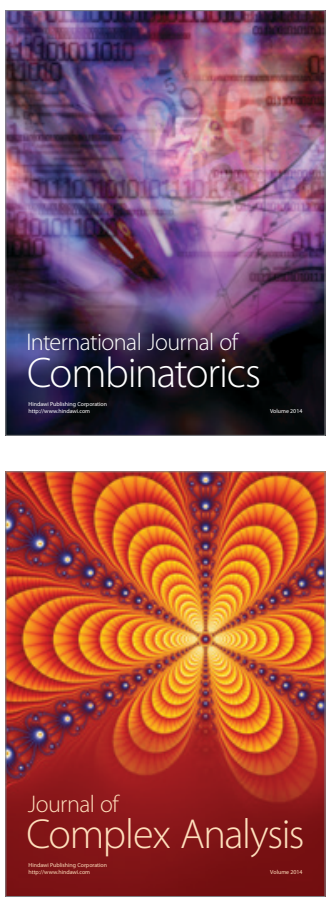

International Journal of

Mathematics and

Mathematical

Sciences
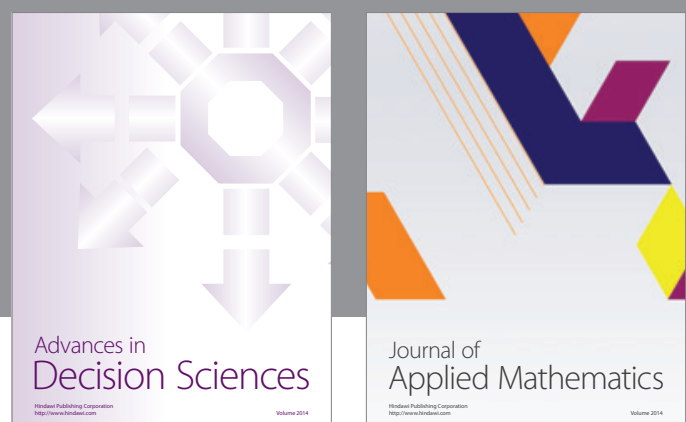

Journal of

Applied Mathematics
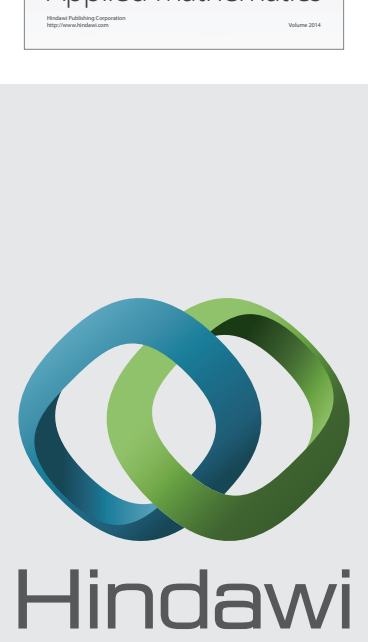

Submit your manuscripts at http://www.hindawi.com
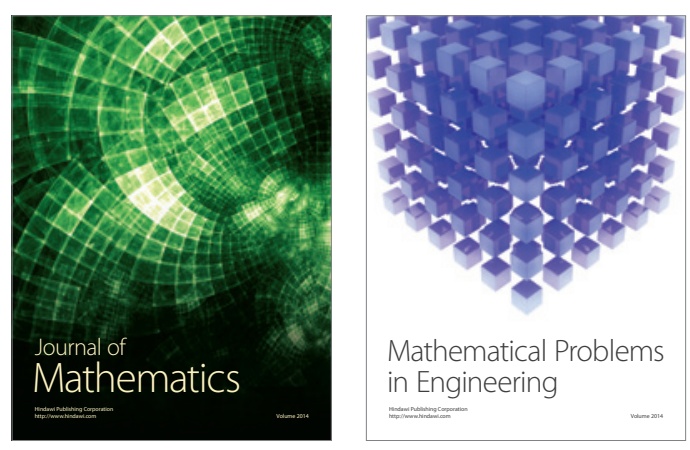

Mathematical Problems in Engineering
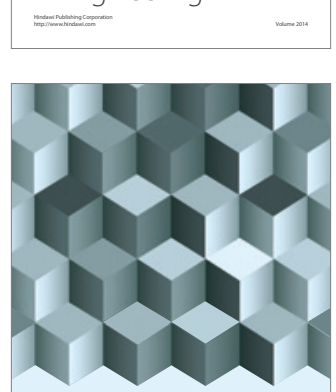

Journal of

Function Spaces
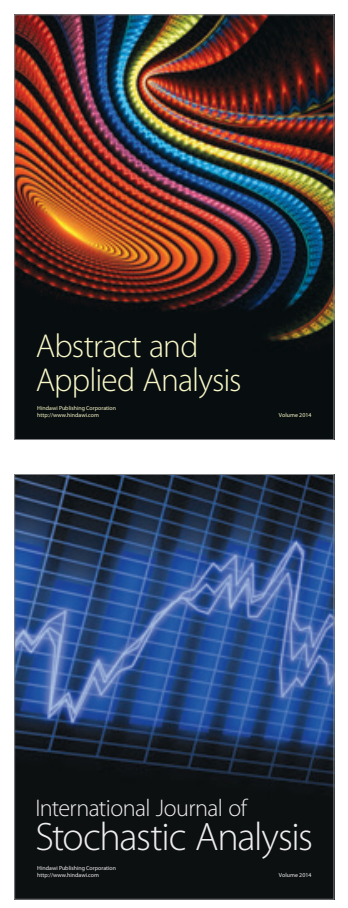

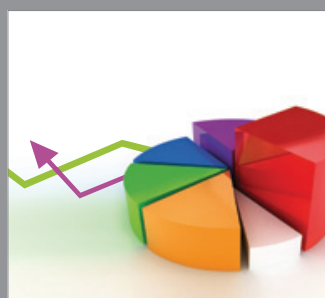

ournal of

Probability and Statistics

Promensencen
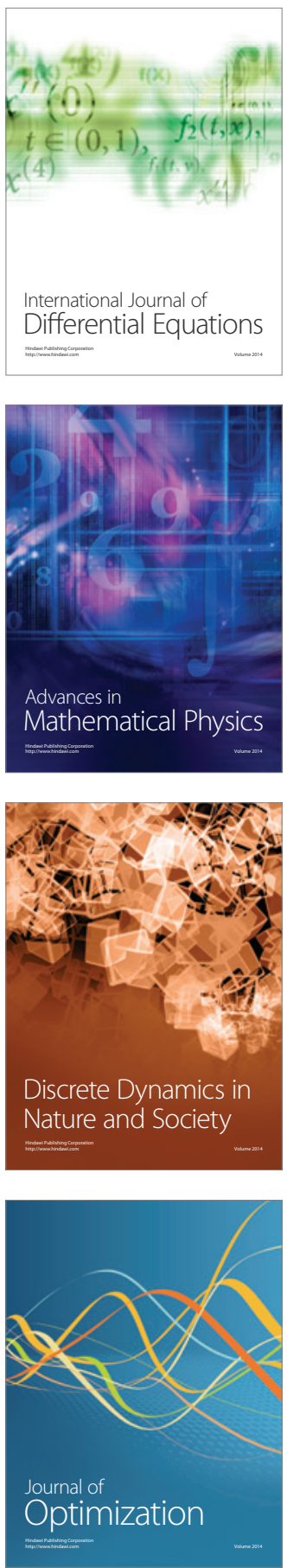